\title{
Antibodies to hepatitis A virus in Italian patients with chronic liver disease
}

\author{
E. SAGNELLI ${ }^{1 *}$, G. ROSSI ${ }^{1}$, N. COPPOLA ${ }^{1}$, C. SCOLASTICO $^{1}$, M. ONOFRIO $^{1}$, \\ P. FILIPPINI ${ }^{1}$, M. CHIARAMONTE ${ }^{2}$, E. PIZZIGALLO ${ }^{3}$, A. ACETI ${ }^{4}$, \\ A. SPADARO ${ }^{5}$, G. RAIMONDO ${ }^{6}$ AND F. PICCININO ${ }^{1}$ \\ ${ }^{1}$ Institute of Infectious Diseases, Second University of Naples \\ ${ }^{2}$ Dipartimento di Scienze Chirurgiche e Gastroenterologiche, University of Padua \\ ${ }^{3}$ Institute of Infectious Disease, University of Chieti \\ ${ }^{4}$ Institute of Infectious Disease, University of Sassari \\ ${ }^{5}$ Clinica Medica la, University of Messina \\ ${ }^{6}$ Dipartimento di Medicina Interna, University of Messina
}

(Accepted 10 May 2001)

\section{SUMMARY}

To improve our knowledge for future hepatitis A virus (HAV) vaccination strategies we carried out a multicentre study on naturally acquired immunological protection against HAV in patients with chronic hepatitis in Italy. We enrolled 830 consecutive patients with chronic hepatitis on their first observation at one of the six Italian liver units participating in the study. Six hundred and fifty-eight patients $(79 \cdot 3 \%)$ were positive for total anti-HAV and $172(20 \cdot 7 \%)$ were negative. The anti-HAV negative patients were younger (median age 33, range 11-78) than the anti-HAV positive (median age 56,18-87). There was a higher prevalence of cases with circulating anti-HAV among the 508 patients residing in southern Italy than in the 322 residing in northern Italy $(88.8 \%$ vs. $64 \%, P<0.001)$. No significant difference in the anti-HAV prevalence was observed between patients from northern Italy and those from southern Italy aged $0-30$ years or in those over 60 years, while in those 31-60 years old there was a higher prevalence of anti-HAV positive patients from southern Italy $(90.2 \% v s .65 .8 \%, P<0.0001)$. Of the patients with liver cirrhosis in this study, only 3 of the $26(11.5 \%)$ from northern Italy and 8 of the $228(3.5 \%)$ from southern Italy had no immunological protection against HAV infection. The data suggest that the number of patients with chronic liver disease without naturally acquired immunity against HAV is substantial in Italy, particularly in the north of the country, and that new vaccination strategies are needed.

\section{INTRODUCTION}

Acute viral hepatitis due to the hepatitis A virus (HAV) is a self-limited disease [1] that is rarely fulminant [2]. However, a higher risk of fulminant hepatitis and death from liver failure has been

* Author for correspondence: Institute of Infectious Diseases, Second University of Naples, c/o Ospedale Gesù e Maria, via D. Cotugno 1, 80135, Naples, Italy. documented in older people [1] and in patients with pre-existing chronic liver disease $[3,4]$.

A marked reduction in the endemicity of HAV infection has been observed in Western countries over the last two decades. This is a consequence of improved sanitation and better socio-economic conditions. There has been a consequent progressive reduction in the spread of this infection in children, teenagers and young adults. In Italy, the incidence of 
HAV-related acute hepatitis declined from 10/100000 cases reported in 1985 to $2 / 100000$ in 1987. It remained constant from 1988 to 1990, and then increased to $6 / 100000$ in subsequent years [5]. This recent increase seems to be due to the widespread consumption of raw shellfish by young adults who are no longer protected against HAV [6-11]. Also in Italy, acute HAV infection in patients with pre-existing chronic hepatitis has been associated with liver failure [12]. Since a vaccine to prevent HAV infection has been shown to be immunologically active, safe, free from severe side effects and generally well tolerated $[13,14]$, we carried out a multicentre nationwide study to explore the naturally developed protection against HAV in patients with chronic hepatitis in order to give the Public Health Authorities more information for new vaccination strategies.

\section{METHODS}

Six Liver Units in Italy, one in the north (Padua), one in the centre (Chieti), one in the south (Naples) of the mainland, one in Sardinia (Sassari) and two in Sicily (both in Messina) participated in the study. These centres have cooperated for years in multicentre studies on chronic hepatitis and adopt a similar clinical approach and similar laboratory technology.

Chronic hepatitis was defined on the basis of the persistence of increased serum aminotransferase values for at least 6 months. We defined cirrhosis as a blood platelet count lower than $100000 / \mathrm{mm}^{3}$ associated with one or more of the following signs: ascites, porto-systemic encephalopathy, oesophageal varices, ultrasound evidence characterizing liver cirrhosis. Only a limited number of patients underwent liver biopsy, so the histological data were not used to assess the severity of the liver disease. The 830 patients enrolled in the study were all consecutive patients with chronic hepatitis on their first observation at 1 of the 6 liver units from January to December 1998. None of them had ever received HAV vaccine. For each patient, a questionnaire was completed to record the demographic, etiological and clinical data.

Anti-HAV antibodies, hepatitis B virus (HBV) serum markers (HBsAg, anti-HBc) and hepatitis D virus antibody (anti-HDV) were determined using commercial immunoenzymatic assays (Abbott Laboratories, North Chicago, IL, USA). The hepatitis $\mathrm{C}$ antibody (anti-HCV) was determined by $3 \mathrm{rd}$ generation commercial immunoenzymatic assay
(Ortho Diagnostic Systems, Neckargemund, Germany).

Autoimmune chronic hepatitis was identified on the basis of histological lesions characterizing the disease and on the presence of non organ specific autoantibodies at a titre of at least 40 , as detected by the indirect immunofluorescent technique: anti-nuclear antibodies of homogeneous pattern for autoimmune hepatitis type 1 and anti-mitochondrial antibodies for primary biliary cirrhosis. Haemochromatosis was a rare histological diagnosis.

An alcohol intake of more than $80 \mathrm{~g}$ daily for males and $40 \mathrm{~g}$ daily for females for at least 10 years was considered as the aetiologic factor in patients with no other aetiologic marker. All other chronic liver diseases with no detectable aetiologic marker were defined as cryptogenic.

Liver function tests were performed according to routine methods.

Differences in means or in proportions were evaluated by the Student $t$ test or by the $\chi^{2}$ test with the Yates correction, respectively. A $P$ value lower than 0.05 was considered as significant.

\section{RESULTS}

The 830 patients in the study (490 males and 340 females) had a median age of 53 years (range 11-87); $616(74.2 \%)$ were anti-HCV positive, $75(9 \%) \mathrm{HBsAg}$ positive, $32(3.9 \%) \mathrm{HBsAg} /$ anti-HCV positive, 3 $(0.4 \%) \mathrm{HBsAg} /$ anti-HCV/anti-HDV positive and 7 $(0.8 \%) \mathrm{HBsAg} /$ anti-HDV positive, $18(2.2 \%)$ had autoimmune hepatitis, $3(0.3 \%)$ idiopathic haemochromatosis, $24(2 \cdot 9 \%)$ chronic alcoholic hepatitis and $52(6 \cdot 3 \%)$ cryptogenic chronic hepatitis.

Six hundred and fifty-eight patients $(79.3 \%)$ were positive for total anti-HAV and $172(20.7 \%)$ were negative. This antibody was detected in $76.9 \%$ of the 490 males and in $82.6 \%$ of the 340 females, a difference that was not statistically significant. The 172 anti-HAV negative patients were younger (median age 33 years, range 11-78 years) than those 658 antiHAV positive (median age 56 years, range 18-87 years).

Table 1 shows the prevalence of anti-HAV positive cases in the different age groups. Anti-HAV in serum was detected less frequently in the under 30 age group $(36.6 \%)$ than in the $31-60$ age groups $(80.6 \%$, $P<0.0001)$ and in the over $60(95.9 \%, P<0.0001)$. The anti-HAV seroprevalence was $63.2 \%$ in the 114 
Table 1. Prevalence of anti-HAV antibodies in 830 subjects with chronic liver disease, according to age, area of residence and severity of liver disease

\begin{tabular}{|c|c|c|c|c|c|c|c|c|c|}
\hline \multirow{3}{*}{$\begin{array}{l}\text { Age groups... } \\
\text { HAV antibody status }\end{array}$} & \multicolumn{3}{|c|}{$0-30$ years } & \multicolumn{3}{|c|}{$31-60$ years } & \multicolumn{3}{|c|}{$>60$ years } \\
\hline & \multirow[b]{2}{*}{ Total } & \multicolumn{2}{|c|}{ with anti-HAV } & \multirow[b]{2}{*}{ Total } & \multicolumn{2}{|c|}{ with anti-HAV } & \multirow[b]{2}{*}{ Total } & \multicolumn{2}{|c|}{ with anti-HAV } \\
\hline & & No. & $(\%)$ & & No. & $(\%)$ & & No. & $(\%)$ \\
\hline Northern Italy & 73 & 25 & $34 \cdot 2$ & 184 & $121 *$ & $65 \cdot 8$ & 65 & 61 & $93 \cdot 9$ \\
\hline Chronic hepatitis & 73 & 25 & $34 \cdot 2$ & 173 & $113 \dagger$ & $65 \cdot 3$ & 50 & 46 & 92 \\
\hline Cirrhosis & - & - & & 11 & $8 *$ & $72 \cdot 7$ & 15 & 15 & 100 \\
\hline Southern Italy & 39 & 16 & 41 & 286 & $258^{*}$ & $90 \cdot 2$ & 183 & 177 & $96 \cdot 7$ \\
\hline Chronic hepatitis & 38 & 16 & 42 & 195 & $169 \dagger$ & $86 \cdot 6$ & 47 & 46 & $97 \cdot 8$ \\
\hline Cirrhosis & 1 & - & & 91 & $89 \%$ & $97 \cdot 8$ & 136 & 131 & $96 \cdot 3$ \\
\hline Italy & 112 & 41 & $36 \cdot 6$ & 470 & 379 & $80 \cdot 6$ & 248 & 238 & $95 \cdot 9$ \\
\hline Chronic hepatitis & 111 & 41 & $36 \cdot 9$ & 368 & $282 \S$ & $76 \cdot 6$ & 97 & 92 & $94 \cdot 8$ \\
\hline Cirrhosis & 1 & - & & 102 & $97 \S$ & $89 \cdot 2$ & 151 & 146 & $96 \cdot 6$ \\
\hline
\end{tabular}

Differences significant to statistical analysis: $* P<0.0001 ; \dagger P<0.0001 ; \ddagger P<0.01 ; \S P<0.01$.

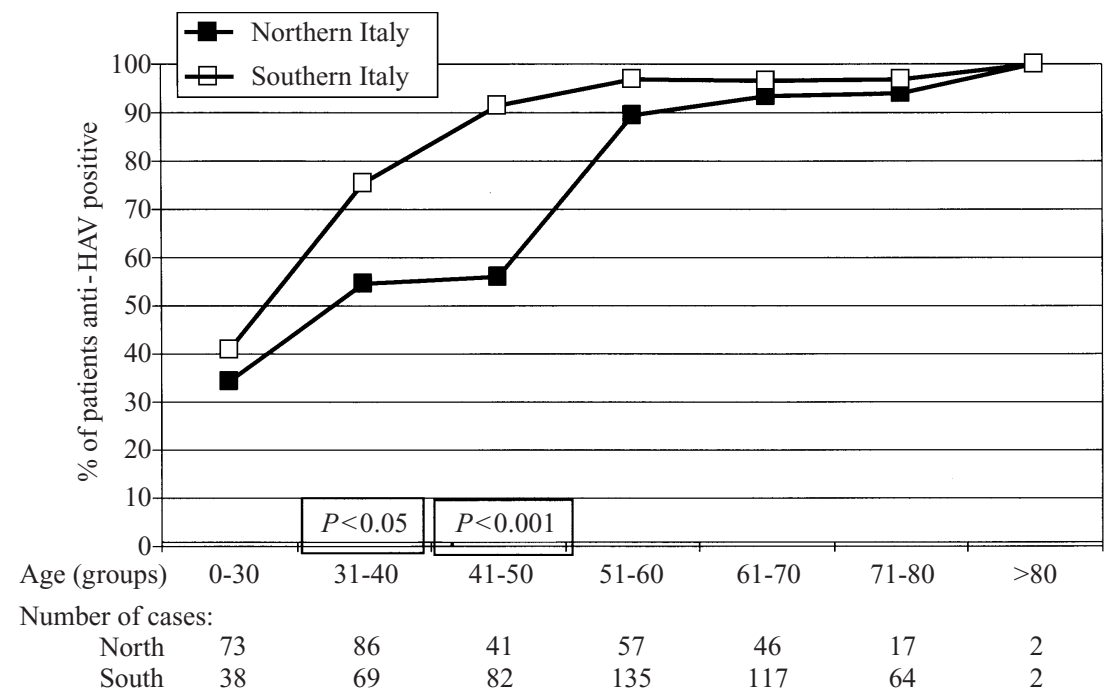

Fig. 1. Anti-HAV prevalence in different age groups, by geographic area.

patients from Padua, $67.9 \%$ in the 109 from Chieti, $60.6 \%$ in the 99 from Sassari, $90 \cdot 2 \%$ in the 194 from Naples and $88.2 \%$ in the 314 from the two centres in Messina.

To analyse the data according to the geographical area of residence, we considered the borderline between the north and south of the country as latitude $41.3^{\circ}$ north, as in our previous investigation on the epidemiology of HDV infection in Italy [15]. In compliance with this division, the 322 patients from the liver units in Padua, Chieti and Sassari were considered as resident in northern Italy and the 508 patients from the units in Naples and Messina as resident in southern Italy. There was a higher prevalence of cases with circulating anti-HAV among those residing in southern Italy than those residing in the north of the country $(88.8 \%$ vs. $64 \%, P<0.001)$.

In southern Italy the anti-HAV prevalence increased with increasing age: $41 \%$ in the $0-30$ age group, $75.4 \%$ in the $31-40$ age group, $91.5 \%$ in the 41-50 age group, etc. (Table 1). In northern Italy there was a similar trend, but the anti-HAV prevalences in the $31-40$ and in the $41-50$ age groups were lower than those found in the corresponding age groups in the south of the country: $54.6 \%$ vs. $75.4 \%(P<0.05)$ and $56.1 \%$ vs. $91.5(P<0.001)$, respectively (Table 1$)$ (Fig. 1).

As for the severity of the liver disease, 254 patients presented unequivocal signs of liver cirrhosis; the remaining 576 patients were classified as chronic 
hepatitis patients. The anti-HAV antibody was more frequently detected in patients with cirrhosis $(95.7 \%$ of cases) than in those with chronic hepatitis $(72 \%$; $P<0.001)$. The median age of the patients with cirrhosis, however, was higher (median age 63, range 11-87) than that of patients with chronic hepatitis without cirrhosis (median age 44.5, range 21-87); thus, it is likely that the former were more frequently anti-HAV positive because they were older.

Table 1 shows the prevalence of anti-HAV in patients with chronic hepatitis according to age, area of residence and severity of the liver disease. This prevalence was low in the $0-30$ age groups, both in northern $(34 \cdot 2 \%)$ and southern (41\%) Italy and no patient had cirrhosis. In the 31-60 age groups, there was a higher prevalence of anti-HAV positive patients from southern Italy than from the north of the country $(90.2 \%$ vs. $65.8 \%, P<0.0001)$; anti-HAV was detected in almost all patients with cirrhosis in the $31-60$ age groups from southern Italy $(97 \cdot 8 \%)$ and with a lower frequency in the corresponding patients from the north of the country $(72.7 \%, P<0.01)$. A similar trend was observed in chronic hepatitis patients with no clinical signs of cirrhosis $(86.6 \% \mathrm{vs}$. $65.3 \%, P<0.0001)$. More than $90 \%$ of the patients in the over 60 age groups were anti-HAV positive both in the north and in the south of the country, regardless of the presence or absence of cirrhosis (Table 1).

Moreover, of all the patients with liver cirrhosis in the study, only 3 of the $26(11.5 \%)$ from the centres in northern Italy and 8 of the $228(3.5 \%)$ from the centres in the south were anti-HAV negative, and thus had no immunologic protection against HAV infection.

\section{DISCUSSION}

The prevalence of natural protection against HAV in patients with chronic liver disease is high in Italy, as $80 \%$ of our patients showed circulating anti-HAV. The percentage of anti-HAV positive patients was significantly higher in southern Italy and this probably reflects lower cultural and socio-economic standards. Moreover, the consumption of raw shellfish, infrequent in the north, is widespread in southern Italy.

Patients with chronic hepatitis aged under 30 years lacked the anti-HAV antibody more frequently than the patients in the older age groups. These differences are statistically significant and are due to a cohort effect reflecting the clear reduction in the HAV endemicity observed in the latter two decades both in northern and southern Italy [5, 16-18]. Noteworthy, however, is the observation that, in the 31-60 age groups, the patients from southern Italy showed a significantly higher percentage of anti-HAV positive cases than the corresponding groups from the north, this difference being particularly evident and statistically significant in the $31-40$ and $41-50$ age groups. Thus, the improvement in socio-economic and sanitary conditions reduced the spread of HAV infection first in northern Italy and a few decades later in the south of the country. As a consequence of the different duration of the conditions responsible for a decreased HAV endemicity, a considerable number of our chronic hepatitis patients aged $0-60$ in northern Italy and of those aged $0-30$ in the south are exposed to HAV infection. Fortunately, the majority of patients with liver cirrhosis, who might be at a higher risk of liver failure following acute HAV infection, show naturally acquired protection against HAV, most probably because of their age. A multivariate analysis of these data was not performed, since only one patient aged under 30 had cirrhosis and few patients with cirrhosis were anti-HAV negative.

We should remember that wherever there has been a decline in the spread of HAV among children and young adults, the symptomatic/asymptomatic ratio has increased and the clinical presentation and clinical course of the disease has worsened. This is due to a shift in the median age of infection to an older age when patients are more frequently symptomatic. Moreover, it is widely accepted that patients with chronic liver disease and, in particular, those with liver cirrhosis should be protected from any factor that may bring about additional liver damage. In an analysis of the data on the HAV epidemiology reported to the Centres for Disease Control and Prevention in Atlanta, USA, from 1983 to 1988, the estimated case fatality rate in patients with an underlying diagnosis of chronic hepatitis B infection was $11.7 \%$, i.e. 58 -fold that of patients with no preexisting liver disease [19]. Moreover, during an epidemic of acute hepatitis A in Shanghai in 1988, caused by the consumption of raw clams mainly by young adults, over 300000 cases occurred and 47 deaths resulted; 15 of these deaths were caused by HAV superimposed on chronic HBV infection [20]. During a 7-year follow-up of 535 anti-HAV negative Italian adults with histological evidence of chronic hepatitis due to HCV (432 patients) or HBV (163 
patients), Vento et al. observed HAV superinfection in 27 cases, 10 with chronic HBV infection and 17 with chronic HCV infection [12]; 7 of the latter 17 had fulminant hepatitis and all but 1 died. However, most Italian centres, including those in our study, do not share this experience.

In December 1996, the Advisory Committee on Immunisation Practices from the Centres for Disease Control and Prevention in Atlanta (USA) recommended active immunization against HAV infection of all patients with chronic liver disease [18], since the new HAV vaccine was shown to be safe and immunologically active, even though the amounts of anti-HAV in patients with liver disease after vaccination are lower than those in healthy subjects [21, 22]. An Italian Consensus Conference held in Rome in 1995 [23] concluded that the lack of epidemiological data on this topic in Italy and the lack of information on the incidence of acute HAV infection in subjects with liver disease did not allow a conclusive statement to be made regarding the immunization strategy to be adopted for patients with chronic hepatitis. HAV immunization was recommended for all patients with chronic liver disease awaiting liver transplantation. However, the data reported here and the recent results of the Italian surveillance programme on acute hepatitis, showing outbreaks of HAV hepatitis in young adults in southern Italy in recent years, indicate that national and/or regional vaccination programmes or guidelines from the Italian Health Authorities are needed for a vaccination campaign against HAV infection for patients with chronic hepatitis. While awaiting the decision of the Health Authorities, we have planned a meeting to propose a controlled clinical trial of vaccination against $\mathrm{HAV}$ in anti-HAV negative patients with chronic liver disease, that is to involve the liver units participating in this study as well as numerous other liver units in Italy.

\section{ACKNOWLEDGEMENTS}

This study was supported by a grant from the Ministry of the University, Scientific Research and Technology (M.U.R.S.T.) ex $40 \%$, Rome, Italy.

\section{REFERENCES}

1 Tong MJ, el-Farra NS, Grew MI. Clinical manifestations of hepatitis $\mathrm{A}$ : recent experience in a community teaching hospital. J Infect Dis 1995; 171 (Suppl 1): S15-8.
2 Willner IR, Uhl MD, Howard SC, Williams EQ, Riely CA, Waters B. Serious hepatitis A: an analysis of patients hospitalized during an urban epidemic in the United States. Ann Intern Med 1998; 128: 111-4.

3 Melnick JL. History and epidemiology of hepatitis A virus. J Infect Dis 1995; 171 (Suppl 1): S2-8.

4 Forbes A, Williams R. Changing epidemiology and clinical aspects of hepatitis A. Br Med Bull 1990; 46: 303-18.

5 Mele A, Stroffolini T, Palumbo F, et al. Incidence of and risk factors for hepatitis A in Italy: public health indications from a 10-year surveillance. J Hepatol 1997; 26: $743-7$.

6 Shapiro CN, Margolis HS. Worldwide epidemiology of hepatitis A virus infection. J Hepatol 1993; 18: S11-4.

7 Mele A, Rastelli MG, Gill ON, et al. Recurrent epidemic hepatitis A associated with consumption of raw shellfish, probably controlled through public health measures. Am J Epidemiol 1989; 130: 540-6.

8 Mele A, Catapano R, Cialdea L, Piscane A, Mladen AS, Kresevic L. Outbreak of hepatitis A in Trieste (Italy). J Publ Hlth Med 1994; 16: 242-4.

9 Lednar WM, Lemon SM, Kirkpatrick JW, Redfield RR, Fields ML, Kelley PW. Frequency of illness associated with epidemic hepatitis A virus infection in adults. Am J Epidemiol 1985; 122: 226-33.

10 Sagliocca L, Mele A, Ferrigno L, et al. Case control study of risk factors for hepatitis A: Naples 1990-1991. Ital J Gastroenterol 1995; 27: 181-4.

11 Stroffolini T, D'Amelio R, Matricardi PM, et al. The changing epidemiology of hepatitis A in Italy. Ital $\mathbf{J}$ Gastroenterol 1993; 25: 372-4.

12 Vento S, Garofano T, Renzini C, et al. Fulminant hepatitis associated with hepatitis A virus superinfection in patients with chronic hepatitis C. N Engl J Med 1998; 29: 286-90.

13 Innis BL, Snitbhan R, Kunasol P, et al. Protection against hepatitis $\mathrm{A}$ by an inactivated vaccine. JAMA 1994; 271 : 1328-34.

14 Werzberger A, Mensch B, Kuter, et al. A controlled trial of a formalin-inactivated hepatitis A vaccine in healthy children. N Engl J Med 1992; 327: 453-7.

15 Sagnelli E, Stroffolini T, Ascione A, et al. The epidemiology of hepatitis delta infection in Italy. J Hepatol 1992; 15: 211-5.

16 Sagnelli E, Liorre G, Mogavero AR, et al. Screening per anti-HAV in pazienti con epatite cronica. Le Infezioni in Medicina 1997; 3: 164-7.

17 Sjogren $\mathrm{MH}$. Preventing acute liver disease in patients with chronic liver disease. Hepatology 1998; 27 : 887-8.

18 Prevention of hepatitis A through active or passive immunization: recommendations of the Advisory Committee on Immunization Practices. MMWR 1996; 45: $1-30$.

19 Keeffe EB. Is hepatitis A more severe in patients with chronic hepatitis B and other chronic liver disease? Am J Gastroenterol 1995; 90: 201-5.

20 Yao G. Clinical spectrum and natural history of viral hepatitis A in a 1988 Shanghai epidemic. In: Hollinger 
FB, Lemon SM, Margolis H, eds. Viral hepatitis and liver disease. Baltimore: Williams \& Wilkins, 1991: 14-20.

21 Lee SD, Chan CY, Yu MI, et al. Safety and immunogenicity of inactivated hepatitis A vaccine in patients with chronic liver disease. J Med Virol 1997; 52: $215-8$.
22 Keefe EB, Iwarson S, McMahon BJ, et al. Safety and immunogenicity of hepatitis A vaccine in patients with chronic liver disease. Hepatology 1998; 27: 881-6.

23 Mele A and Workshop Consensus Conference. Antihepatitis A virus (HAV) vaccination: guidelines for an immunization strategy in Italy. Ital J Gastroenterol 1996; 28: 181-4. 